\title{
Exposure and Sensitization to Pets Modify Endotoxin Association with Asthma and Wheeze
}

\author{
Angelico Mendy, MD, MPHa ${ }^{a}$ Jesse Wilkerson, BS ${ }^{b}$, Päivi M. Salo, PhD $^{c}$, Richard D. Cohn, \\ $\mathbf{P h D}^{\mathrm{b}}$, Darryl C. Zeldin, $\mathbf{M D}^{\mathrm{c}}$, and Peter S. Thorne, $\mathrm{PhD}^{\mathrm{a}}$ \\ aDepartment of Occupational and Environmental Health, University of lowa, lowa City, lowa \\ bSocial \& Scientific Systems, Inc., Durham, North Carolina \\ 'Division of Intramural Research, National Institute of Environmental Health Sciences, NIH \\ Research Triangle Park, North Carolina
}

\section{Abstract}

BACKGROUND—Pets are major contributors of endotoxin in homes, but whether they influence endotoxin association with respiratory outcomes is unclear.

\begin{abstract}
OBJECTIVE-To examine whether exposure and sensitization to dog and cat modify the relationship between endotoxin exposure and asthma and wheeze.

METHODS-We analyzed data from 6,051 participants in the 2005-2006 National Health and Nutrition Examination Survey (NHANES). House dust from bedroom floor and bedding was evaluated for endotoxin and for dog (Canis familiaris 1 ) and cat (Feline domesticus 1 ) allergens. The NHANES also collected data on respiratory outcomes and measured immunoglobulin E specific to allergens. Associations of log-endotoxin and pet exposure with respiratory outcomes were examined adjusting for covariates including pet avoidance.
\end{abstract}

RESULTS-Dog and cat ownership among participants was $48.3 \%$ and $37.5 \%$, respectively. Endotoxin geometric mean (standard error) was 15.49 (0.50) EU/mg. Endotoxin and pet allergen levels were significantly higher in households with a dog or cat. Overall, endotoxin was positively associated with wheeze (OR 1.30 [95\% CI: 1.04-1.62]), but not with asthma. However, in participants non-sensitized to dog, the odds of endotoxin association with wheeze was higher with exposure to dog allergen (OR 1.80 [1.27-2.53], $\left.P_{\text {interaction }}=0.048\right)$. In participants sensitized to cat and exposed to cat allergen, endotoxin became positively associated with asthma (OR 1.92 [1.213.0], $P_{\text {interaction }}=0.040$ ). With co-exposure to dog and cat allergens, endotoxin association with asthma and wheeze was exacerbated (OR 2.00 [1.04-3.83], $P_{\text {interaction }}=0.012$ and OR 1.88 [1.322.66], $P_{\text {interaction }}=0.016$ respectively).

\footnotetext{
Corresponding Author: Peter S. Thorne, PhD, University of Iowa College of Public Health, 100 CPHB, S341A, 145 N Riverside Dr. Iowa City, IA 52242-2207, Phone: (319) 335-4216, peter-thorne@uiowa.edu.

Author Contributions: Angelico Mendy assisted with development of the research questions and data analysis and was principal author of this manuscript. Peter S. Thorne directed the endotoxin analysis of the NHANES samples, contributed to the study design, collaborated on development of the research questions and edited the manuscript. Darryl C. Zeldin and Päivi Salo contributed to the conception, hypothesis delineation and design of this component of the NHANES study. Jesse Wilkerson and Richard D. Cohn contributed to the statistical analysis and interpretation of the data. All authors provided edits and comments on the manuscript. 
CONCLUSION-Exposure to dog and cat allergens enhances the association of endotoxin with asthma and wheeze.

\section{Keywords}

Endotoxin; Pets; Asthma; Wheeze; Sensitization; House dust

\section{INTRODUCTION}

Endotoxin is a lipopolysaccharide from the outer membrane of Gram-negative bacteria that persists in the environment after bacterial death (1). It is widely disseminated in our surroundings and higher concentrations are found in occupational settings where large quantities of bio-aerosols are generated $(2,3)$. Endotoxin has pro-inflammatory properties and can cause wheeze as well as increase in asthma severity $(1,4,5)$. The pathophysiology of this inflammation involves the activation of macrophages with the release of proinflammatory cytokines (tumor necrosis factor-a [TNF-a] and interleukins [IL] $-1,-6$, and -8) (1, 4-6). However, there are reports that early childhood exposure to low doses of endotoxin could protect against atopic asthma and allergy in genetically predisposed individuals, potentially due to immune-modulatory effects by the lipopolysaccharide (6).

The presence of pets is a major contributor of endotoxin in homes $(2,7)$. Exposure to dog or cat has also been reported to have either positive or negative associations with asthma and wheeze, depending on the timing of exposure and family history of asthma (8-10). It is possible that some of these associations could be mediated by endotoxin, but it has been suggested that the effect of pets on respiratory symptoms might well be independent of endotoxin (11). Although exposure to both endotoxin and pets could each be associated with asthma and wheeze, it is still unclear if they interact to affect respiratory outcomes. In particular, since pets are major predictors of endotoxin in homes, it has been difficult to separate the two exposures. Therefore, we proposed to investigate the influence of exposure and sensitization to dog and cat on the endotoxin association with asthma and wheeze in a sample representative of the U.S. population.

\section{MATERIALS AND METHODS}

\section{Data source and study design}

Data for the analysis were obtained from the 2005-2006 cycle of the National Health and Nutrition Examination Survey (NHANES). The NHANES is a continuous cross-sectional survey of the U.S. non-institutionalized civilian population conducted by the National Center for Health Statistics (NCHS) of the Centers for Disease Control and Prevention (CDC). It uses a complex multistage sampling design to derive a sample representative of the U.S. population. Some subgroups such as participants below the poverty level, teenagers 12 to 19 years of age, people 60 years or older, pregnant women, African Americans, and Mexican Americans were oversampled to ensure adequate subgroup analyses. Of the 6,963 NHANES participants who had data on house dust endotoxin, a total of 6,051 (86.9\%) had data on pet ownership as well as on sensitization to pets and were included in our study. The study 
sample consisted of 5,494 participants who had data on exposure and sensitization to dog, and of 4,808 participants who had data on exposure and sensitization to cat.

NHANES protocols were approved by the Institutional Review Boards of the NCHS and $\mathrm{CDC}$ and informed consent was obtained from all participants. Details of the IRB approval are available on http://www.cdc.gov/nchs/nhanes/irba98.htm. NHANES procedures and methods are further described on http://www.cdc.gov/nchs/nhanes/survey_methods.htm.

\section{Endotoxin Analysis}

Combined bed and bedroom floor dust samples were collected at each participant's home using a vacuum cleaner fitted with a Mitest ${ }^{\mathrm{TM}}$ Dust Collector (Indoor Biotechnologies, Inc., Charlottesville, VA). One-square yard surfaces on beds and the adjacent floors were each vacuumed for two minutes. These composite dust samples were analyzed for endotoxin at our University of Iowa laboratory using a kinetic chromogenic Limulus amebocyte lysate assay with expansive quality assurance measures as previously described (4). Sieved dust was extracted with sterile pyrogen-free water plus $0.05 \%$ Tween- $20^{\mathrm{TM}}$. Control standard endotoxin (E. coli 055:B5) was used to develop 12-point standard curves and samples were assayed at four dilutions increasing four-fold from 1:400 to 1:25,600. Endotoxin concentrations were reported in endotoxin units per sieved dust weight (EU/mg of dust). The lower limit of detection was $0.000488 \mathrm{EU} / \mathrm{mg}$. A detailed description of our laboratory methods for the endotoxin assay is available at: http://www.cdc.gov/nchs/data/nhanes/ nhanes_05_06/ALDUST_D_met_endotoxin.pdf.

\section{Pet ownership in past 12 months}

In the Housing Characteristics section of the NHANES questionnaire, participants were asked about the presence of pets in the home ("Do any dogs, cats, and furry animals such as a rabbit, a guinea pig or hamster live or spend time in your home?'). Current presence of dog or cat in the home was based on the answer to the follow-up question "What kind of pet is it?' to participants who provided a positive answer to the previous question. Participants who provided a negative answer to the first question were secondarily asked about the past presence of pet in the home in the past 12 months ("In the last 12 months, did any dogs, cats, and furry animals such as a rabbit, a guinea pig or hamster live or spend time inside your home?'). Again, they were classified as having had a dog or a cat in the past 12 months, based on their answer to the question "What kind of pet was it?' In our analysis, we combined current and past 12 month-presence of pets in home, to define pet ownership in the past 12 months.

\section{Pet allergens and sensitization to pets}

Dust samples from homes were analyzed for a panel of allergens including dog (Canis familiaris $[\mathrm{Can} f]$ ) and cat (Feline domesticus $[\mathrm{Fel} d] 1$ ) allergens using a Multiplex Array for Indoor Allergens assay (MARIA; Indoor Biotechnologies, Charlottesville, VA). Serum IgE specific to dog and cat dander were measured using the Pharmacia Diagnostics ImmunoCAP 1000 System (Kalamazoo, Michigan), now known as Thermo Scientific ${ }^{\text {TM }}$ ImmunoCAP Specific IgE. Sensitization status was defined as specific IgE $\searrow 0.35 \mathrm{kU} / \mathrm{L}$. 


\section{Asthma and wheeze definition}

Current asthma was defined using the questions: "Has a doctor or other health professional ever told \{you/study participant\} that \{you/s/he had\} asthma?' and "Do you still have asthma?' Wheeze in past 12 months was assessed using the question: "In the past 12 months \{have you/has study participant\} had wheezing or whistling in \{your/his/her\} chest?'

\section{Covariates}

Data on age, gender, race/ethnicity, and family income were collected using questionnaires. Participants were considered as being exposed to cigarette if 1) they had smoker(s) in their homes, 2) if they reported being current or former smokers, and 3) if they had a serum cotinine levels $\geq 10 \mathrm{ng} / \mathrm{ml}$. Poverty income ratio (PIR) was estimated using guidelines and adjustment for family size, year and state. Participants were also asked if they avoided or removed a pet in the last 12 months because of allergies or asthma.

Sensitization to other inhalant allergens was defined as serum specific IgE against any of 13 allergens $\searrow 0.35 \mathrm{kU} / \mathrm{L}$. These included Alternaria alternata, Aspergillus fumigatus, Bermuda grass, birch, cockroach, dust mites [Der $p 1$ and $\operatorname{Der} f 1$ ], mouse urine proteins, oak, ragweed, rat urine proteins, Russian thistle, or rye grass.

\section{Statistical Analysis}

P-values for differences in proportions or means by presence of pet in the home and by sensitization status were calculated using chi-square test for categorical variables and Student t-test for continuous variables. Endotoxin and dog and cat allergens were logtransformed to improve the normality of their distribution. Multivariable logistic regression was used to assess the association of exposure to endotoxin and exposure as well as sensitization to pet with current asthma and wheeze in the past 12 months. Odds ratios (OR) with corresponding confidence intervals (CI) were reported. The models were adjusted for age, gender, race/ethnicity, PIR, exposure to cigarette smoke, and pet avoidance or removal in the last 12 months, and sensitization to other inhalant allergens. Subgroup analyses were conducted stratifying by dog and cat sensitization, pet ownership, and by levels of dog and cat allergens. Low and high dog and cat allergens were defined as levels below or above the median (i.e. $0.41 \mathrm{ng} / \mathrm{mg}$ for $\mathrm{Can} f 1$ and $0.26 \mathrm{ng} / \mathrm{mg}$ for $\mathrm{Fel} \mathrm{d}$ 1). We tested exposure and sensitization to pets for effect modification on endotoxin association of the respiratory outcome by including an interaction term in the model. Interactions for dog and cat allergens were tested using their continuous log-transformed values. The effect of endotoxin on the outcomes was graphically illustrated for the different categories of the modifier using the marginsplot command from STATA (Version 14.2, STATACorp, College Station, TX USA) (12). All analyses were performed in SAS (Version 9.4, SAS Institute, Cary, NC USA). NHANES sample weights were used in all analyses to obtain unbiased national estimates. Standard errors (SE), confidence intervals (CI), and P-values were developed in accordance with the complex survey design by using Taylor series linearization methods. P-values $<0.05$ were considered statistically significant. 


\section{RESULTS}

\section{Characteristics of study participants}

In our sample population, $48.3 \%$ of participants owned a dog and $37.5 \%$ owned a cat. The geometric means (GM) and SE were $15.49(0.50) \mathrm{EU} / \mathrm{mg}$ for endotoxin, $0.59(0.09) \mathrm{ng} / \mathrm{mg}$ for dog allergen, and $0.52(0.07) \mathrm{ng} / \mathrm{mg}$ for cat allergen in house dust. GM (SE) endotoxin levels were $18.41(0.71) \mathrm{EU} / \mathrm{mg}$ for households with dogs, 17.23 (0.76) EU/mg with cats, 21.60 (1.39) EU/mg with both and 13.64 (0.72) EU/mg with no pets. There was a weak, but significant association of dog and cat allergens with endotoxin (regression coefficients 0.08 , $\mathrm{P}<0.0001$, r-squared 0.032 and $0.07, \mathrm{P}<0.0001$, $\mathrm{r}$-squared: 0.028 respectively). The relationships are graphically depicted in the supplemental figures 1 and 2 of the online supplement.

As shown in Table 1, participants who owned a dog compared to those who did not were more likely to be children 6 to 17 years of age and non-Hispanic Whites. They had a higher socioeconomic status (i.e. PIR $\geq 1.85$ ) and higher prevalence of sensitization to inhalant allergens, exposure to cigarette smoke, current asthma or wheeze in the past 12 months, but lower prevalence of pet avoidance. They also had higher house dust concentrations of endotoxin and dog allergen. The characteristics of the participants by sensitization to dog among participants with and without a dog are shown in Table 1.

Table 2 shows that people who owned a cat compared to those who did not were disproportionately children 6 to 17 years of age, non-Hispanic Whites, and people with a higher socio-economic status (i.e. PIR 21.85 ). They also had higher prevalence of sensitization to inhalant allergens, exposure to cigarette smoke, and wheeze. They had less pet avoidance and higher house dust concentration of endotoxin and cat allergen. The characteristics of the participants by sensitization to cat among participants who owned or did not own a cat are reported in Table 2 .

\section{Associations of endotoxin and pet exposure with asthma and wheeze}

As displayed in Table 3, sensitization to dog (OR 3.08, 95\% CI: 1.57-6.01), cat ownership (OR 1.59, 95\% CI 1.15-2.19), cat allergen (OR 1.10, 95\% CI 1.00-1.21 for a 10-fold increase), and sensitization to cat (OR $2.35,95 \%$ CI: $1.55-3.54$ ) were positively associated with current asthma. On the other hand, endotoxin (OR 1.04, 95\% CI: 1.04-1.62 for a 10fold increase), dog ownership (OR 1.50, 95\% CI: 1.17-1.91), dog allergen (OR 1.11, 95\% CI: $1.05-1.19$ for a 10-fold increase), and sensitization to dog (OR 1.82, 95\% CI: 1.44-2.28) were positively associated with wheeze in the past 12 months. The odds of wheeze in the past 12 months was also higher in participants who owned a cat (OR: 1.71, 95\% CI: 1.22 2.39), who were exposed to cat allergen (OR: 1.12 , $95 \%$ CI: $1.01-1.25$ for a 10 -fold increase), or who were sensitized to cat (OR: 1.59, 95\% CI: 1.23-2.06).

The association between the exposures and the outcomes varied by age.

- In children $<6$ year of age, dog ownership was negatively associated with current asthma. 
- In children 6-17 year of age, endotoxin was positively associated with wheeze in the past 12 months. Sensitization to dog and sensitization to cat was positively associated with current asthma and wheeze in the past 12 months.

- In adults aged 18 year or older, dog ownership, sensitization to dog, cat ownership, cat allergen, and sensitization to cat were positively associated with current asthma and wheeze in the past 12 months. Endotoxin and dog allergen had positive associations with wheeze in the past 12 months (Table 3).

\section{Effect modification by exposure to dog}

In participants not sensitized to dog, endotoxin association with wheeze in the past 12 months was higher with elevated exposure to dog allergen (i.e. above median) (OR 1.80, $95 \%$ CI: 1.27, 2.53) than with lower exposure to dog allergen (i.e. below median) (OR 1.01, 95\% CI: 0.77-1.31) $\left(\mathrm{P}_{\text {interaction }}=0.048\right)($ Table 4).

\section{Effect modification by exposure to cat}

In participants sensitized to cat, endotoxin association with current asthma was modified by exposure to cat allergen $\left(\mathrm{P}_{\text {interaction }}=0.040\right)$. Although not associated with current asthma in the overall sample (Table 3), endotoxin became positively associated with current asthma in participants sensitized to cat who were exposed to cat allergen in house dust (i.e. above the median) (OR: 1.92, 95\% CI: 1.21-3.02) (Table 4).

In subgroup analysis by age group reported in Supplemental Table 1, the odds of endotoxin association with wheeze in the past 12 months was significantly higher in participants 6 to 17 year-old who were exposed to cat and cat allergens, but were not sensitized to cat.

\section{Effect modification by co-exposure to dog and cat}

Co-exposure to dog and cat allergens modified endotoxin association with both current asthma $\left(\mathrm{P}_{\text {interaction }}=0.012\right)$ and wheeze in the past 12 months $\left(\mathrm{P}_{\text {interaction }}=0.016\right)$.

Participants living in homes with high dog and cat allergens were more likely to have current asthma and wheeze in the past 12 months when exposed to endotoxin (OR: 2.00, 95\% CI 1.04-3.83 and OR: $1.88,95 \%$ CI 1.32-2.66 respectively for a 10-fold increase in endotoxin) (Table 5). Figure 1 illustrates the increased probability of current asthma (Figure 1a) and wheeze in the past 12 months (Figure 1b) associated with endotoxin in the case of high exposure to dog and cat allergens compared to low exposure to dog and/or cat allergen.

\section{DISCUSSION}

The present study used a large sample representative of the US population to examine how the exposure and the sensitization to pets modify the association of endotoxin with asthma and wheeze. The results suggest that exposure to cat and dog allergens enhances endotoxin relationship with current asthma and wheeze in the past 12 months. In participants nonsensitized to dog, the odds of endotoxin association with wheeze in the past 12 months was higher with exposure to dog allergens. However, in individuals sensitized to cat and exposed to cat allergens in house dust, endotoxin was significantly associated with current asthma. 
Endotoxin association with both current asthma and wheeze in the past 12 months also increased with co-exposure to cat and dog allergens.

To the best of our knowledge, only one study (the Cincinnati Childhood Asthma and Air Pollution study [CCAAPS]) investigated the influence of exposure to pets on endotoxin association with respiratory outcomes (13). In the CCAAPS, Campo et al. studied 532 infants and found that endotoxin was associated with lower odds of recurrent wheeze at age 1-year in the presence of multiple dogs in the house (13). One potential reason these results are inconsistent with our findings was that CCAAPS only included young children whereas NHANES included young children, adolescents and adults. Consistent with our findings, the effect of exposure to pet and endotoxin as well as atopy on asthma or wheeze seems to be age-dependent (14-18). However, in our subgroup analyses by age groups, we did not observe a negative association between endotoxin and wheeze in children who owned a dog or who had high exposure to dog allergens. It is possible that our analysis in children (especially those younger than 6) was underpowered, limiting our ability to find a significant associations. Concordant with the hypothesis that exposure to dog could exacerbate the association of environmental exposures with asthma symptoms, McConnell et al. found that the relationship between air pollution and asthma symptoms was enhanced by dog ownership (19). Our study is the first to examine the effect modification by dog allergen, cat ownership or cat allergen as well as sensitization to cat and dog on the association of endotoxin with asthma and wheeze $(10,20)$. Newton et al. recently investigated the influence of sensitization to mouse on endotoxin-associated symptoms (21).

We found the levels of dog allergen to be a significant effect modifier, while dog ownership had little to no influence on endotoxin association with wheeze. The precise mechanism(s) for this is unclear. It is possible that dog allergens concentration was an indicator for the number of dogs in the home. Dog and endotoxin exposures have been reported to have the similar effect of being hypoallergenic early in life at low concentrations, while having proinflammatory properties $(18,22)$. Consistent with this postulate, we found dog negatively associated with current asthma children younger than 6-year of age, but positively associated with the outcome in adults. This change in effect with age was less apparent for endotoxin. Dogs promote a higher distribution of microbes among household members, resulting in a shared and diverse microbiota protective against allergic conditions $(23,24)$. Ingestion of house dust with a rich microbiome during infancy purportedly modifies the gut microbiota, shapes the immune system and subsequently reduces the risk of allergic asthma (25). In mice, dust from a house with a dog has been shown to protect against allergen-induced airway challenge via the reduction of T-helper (Th)-2 cytokines and fewer activated T-cells (23). Since dogs are major predictors of endotoxin in homes, it has been difficult to separate the two exposures in previous studies, though in some studies, the association of dog exposure with asthma was reported to be independent of endotoxin $(18,19)$. In support of our findings, dog allergens ( $\operatorname{Can} f$ ) have been shown to influence endotoxin action through the enhancement of the interaction of lipopolysaccharides with toll-like receptors in macrophages to cause airway hypersensitivity and wheeze (26). Additionally, pet activity could carry outdoor allergens indoors, increasing the concentration of indoor allergens with higher airborne inhalable exposures which may potentiate endotoxin inflammatory effects (19). Cats have been suggested to have a limited impact on the concentrations of other 
allergens in homes or to have less direct contact with humans compared with dogs (27). Yet, we found that endotoxin was higher in homes with a cat and that with cat exposure, endotoxin became associated with asthma. To possibly explain our results, it has been shown that when cat allergens of the Fel $d 1$ type are inhaled, they can have an increased allergenicity by binding to dendritic cell mannose receptors and causing the secretion of specific immunoglobulins (Ig)-E and G1 (28). This is further supported by reports of higher Fel $d 1$ specific-IgE levels in asthmatic children compared to non-asthmatic controls (2830). In animal studies, endotoxin aggravated inflammation caused by allergen challenge in rats previously sensitized. However, when exposure to endotoxin precedes sensitization, it seems to alleviate allergen-induced airway hyper-responsiveness $(31,32)$. This is coherent with a stronger effect of endotoxin on the risk of asthma in participants previously sensitized to cats or exposed to higher concentration of cat and dog allergens in their homes.

Our study has some limitations. First, the study design was cross-sectional, therefore temporality between the exposures and the outcomes could not be assessed and causality cannot be inferred. The outcomes of asthma and wheeze were self-reported and could not be verified. Endotoxin was measured only once, yet it has been suggested that endotoxin in bed and or bedroom floor is not subject to significant change for up to a year (33). It has been proposed that endotoxin in house dust might not correlate well with endotoxin concentration in air that is inhaled (34). The NHANES also did not include data on the number of pets in the homes. Another limitation was the limited power to examine the effect modification by exposure and sensitization to pets in children younger than 6 year of age. Nonetheless, our study had major strength. It includes a large sample representative of the US population. Dog exposure was defined by pet ownership and exposure to pet allergens, which can be found in homes even in the absence of dog. Prior studies on pet exposure and asthma or wheeze could have been confounded by avoidance behavior towards pets by people who perceive themselves to be at risk. Our analyses adjusted for pet avoidance and removal, but there is still a possibility that pet keeping might be associated with different behaviors we cannot account for. In additional analyses, our results remained significant even after adjustment for sensitization to other allergens associated with asthma and wheeze, reducing the likelihood that other exposures confounded our analysis.

In conclusion, exposure to dog allergen increases the odds of endotoxin association with wheeze in individuals non-sensitized to dog, while in people sensitized to cat and exposed to cat allergens, endotoxin is associated with asthma. Co-exposure to both dog and cat allergens significantly increases endotoxin association with asthma and wheeze. Future studies should evaluate whether environmental measures aimed at reducing the levels of cat and dog allergens as well as endotoxin in the homes of people who want to keep their pets can be effective in reducing asthma and wheeze symptoms in the long-term. Studies should be designed to allow stratification of the analysis by both exposure to pet allergens and sensitization status.

\section{Supplementary Material}

Refer to Web version on PubMed Central for supplementary material. 


\section{ACKNOWLEDGMENT}

The authors acknowledge Dr. Nervana Metwali for leading the analysis of the NHANES dust samples for endotoxin.

Funding: Sample extraction and endotoxin analysis work at the University of Iowa was funded by CDC/NCHS (200-2010-34238 NCE1). Data analysis was funded through a grant to the University of Iowa, Environmental Health Sciences Research Center (NIH P30 ES005605), the University of Iowa Center for Health Effects of Environmental Contamination (CHEEC), and through a contract to Social \& Scientific Systems, Inc. (HHSN273201600002). This work was also funded, in part, by the Intramural Research Program of the NIH, National Institute of Environmental Health Sciences (NIH Z01 ES025041).

\section{Abbreviations}

Can $\mathbf{f} 1$

CDC

CI

Fel d 1

EU

GM

IgE

IL

NCHS

NHANES

OR

PIR

SE

TNF-a

\section{Canis familiaris 1}

Centers for Disease Control and Prevention

Confidence Interval

Feline domesticus 1

Endotoxin Units

Geometric Mean

Immunoglobulin $\mathrm{E}$

Interleukin

National Center for Health Statistics

National Health and Nutrition Examination Survey

Odds Ratio

Ratio of Income to Poverty

Standard Error

Tumor Necrosis Factor- $a$

\section{References}

1. Thorne PS, Kulhankova K, Yin M, Cohn R, Arbes SJ,Jr, Zeldin DC. Endotoxin exposure is a risk factor for asthma: the national survey of endotoxin in United States housing. Am J Respir Crit Care Med. 2005;172(11):1371-7. [PubMed: 16141442]

2. Thorne PS, Cohn RD, Mav D, Arbes SJ, Zeldin DC. Predictors of endotoxin levels in US housing. Environ Health Perspect. 2009;117(5):763. [PubMed: 19479019]

3. Thorne PS. Inhalation toxicology models of endotoxin-and bioaerosol-induced inflammation. Toxicology. 2000;152(1):13-23. [PubMed: 11090935]

4. Thorne PS, Mendy A, Metwali N, Salo P, Co C, Jaramillo R, Rose KM, Zeldin DC. Endotoxin exposure: predictors and prevalence of associated asthma outcomes in the U.S. Am J Respir Crit Care Med. 2015;192(11):1287-97. [PubMed: 26258643]

5. Park JH, Gold DR, Spiegelman DL, Burge HA, Milton DK. House dust endotoxin and wheeze in the first year of life. Am J Respir Crit Care Med. 2001;163(2):322-8. [PubMed: 11179100] 
6. Radon K The two sides of the "endotoxin coin". Occup Environ Med. 2006;63(1):73,8, 10. [PubMed: 16361410]

7. Park JH, Spiegelman DL, Gold DR, Burge HA, Milton DK. Predictors of airborne endotoxin in the home. Environ Health Perspect. 2001;109(8):859-64. [PubMed: 11564624]

8. Litonjua AA, Milton DK, Celedon JC, Ryan L, Weiss ST, Gold DR. A longitudinal analysis of wheezing in young children: the independent effects of early life exposure to house dust endotoxin, allergens, and pets. J Allergy Clin Immunol. 2002;110(5):736-42. [PubMed: 12417882]

9. Celedón JC, Litonjua AA, Ryan L, Platts-Mills T, Weiss ST, Gold DR. Exposure to cat allergen, maternal history of asthma, and wheezing in first 5 years of life. The Lancet. 2002;360(9335):7812.

10. Perzanowski MS, Rönmark E, Platts-Mills TA, Lundbäck B. Effect of cat and dog ownership on sensitization and development of asthma among preteenage children. Am J Respir Crit Care Med. 2002;166(5):696-702. [PubMed: 12204868]

11. Litonjua AA, Milton DK, Celedon JC, Ryan L, Weiss ST, Gold DR. A longitudinal analysis of wheezing in young children: the independent effects of early life exposure to house dust endotoxin, allergens, and pets. J Allergy Clin Immunol. 2002;110(5):736-42. [PubMed: 12417882]

12. Williams R Using the margins command to estimate and interpret adjusted predictions and marginal effects. Stata Journal. 2012;12(2):308.

13. Campo P, Kalra HK, Levin L, Reponen T, Olds R, Lummus ZL, et al. Influence of dog ownership and high endotoxin on wheezing and atopy during infancy. J Allergy Clin Immunol. 2006;118(6): 1271-8. [PubMed: 17157656]

14. Waser M, Von Mutius E, Riedler J, Nowak D, Maisch S, Carr D, et al. Exposure to pets, and the association with hay fever, asthma, and atopic sensitization in rural children. Allergy. 2005;60(2): 177-84. [PubMed: 15647038]

15. Almqvist C, Egmar A, Hedlin G, Lundqvist M, Nordvall S, Pershagen G, et al. Direct and indirect exposure to pets-risk of sensitization and asthma at 4 years in a birth cohort. Clin Exp Allergy. 2003;33(9):1190-7. [PubMed: 12956738]

16. Hesselmar B, Aberg N, Aberg B, Eriksson B, Bjorksten B. Does early exposure to cat or dog protect against later allergy development? Clin Exp Allergy. 1999;29(5):611-7. [PubMed: 10231320]

17. Bufford J, Reardon C, Li Z, Roberg K, DaSilva D, Eggleston P, et al. Effects of dog ownership in early childhood on immune development and atopic diseases. Clin Exp Allergy. 2008;38(10): 1635-43. [PubMed: 18702654]

18. Svanes C, Heinrich J, Jarvis D, Chinn S, Omenaas E, Gulsvik A, et al. Pet-keeping in childhood and adult asthma and hay fever: European community respiratory health survey. J Allergy Clin Immunol. 2003;112(2):289-300. [PubMed: 12897734]

19. McConnell R, Berhane K, Molitor J, Gilliland F, Künzli N, Thorne PS, et al. Dog ownership enhances symptomatic responses to air pollution in children with asthma. Environ Health Perspect. 2006:1910-5. [PubMed: 17185284]

20. Polk S, Sunyer J, Muñoz-Ortiz L, Barnes M, Torrent M, Figueroa C, et al. A prospective study of Fel d1 and Der p1 exposure in infancy and childhood wheezing. Am J Respir Crit Care Med. 2004;170(3):273-8. [PubMed: 15117746]

21. Newton AN, Davis M, Koehler K, Shreffler W, Ahluwalia S, Metwali N, et al. Atopy as a Modifier of the Relationships Between Endotoxin Exposure and Symptoms Among Laboratory Animal Workers. Ann Work Expo Health. 2017;61(8):1024-8. [PubMed: 29028247]

22. Nafstad P, Magnus P, Gaarder P, Jaakkola J. Exposure to pets and atopy-related diseases in the first 4 years of life. Allergy. 2001;56(4):307-12. [PubMed: 11284797]

23. Fujimura KE, Demoor T, Rauch M, Faruqi AA, Jang S, Johnson CC, et al. House dust exposure mediates gut microbiome Lactobacillus enrichment and airway immune defense against allergens and virus infection. Proc Natl Acad Sci USA. 2014;111(2):805-10. [PubMed: 24344318]

24. Song SJ, Lauber C, Costello EK, Lozupone CA, Humphrey G, Berg-Lyons D, et al. Cohabiting family members share microbiota with one another and with their dogs. Elife. 2013;2:e00458. [PubMed: 23599893] 
25. Huang YJ, Boushey HA. The microbiome in asthma. J Allergy Clin Immunol. 2015;135(1):25-30. [PubMed: 25567040]

26. Gómez-Casado C, Díaz-Perales A. Allergen-Associated Immunomodulators: Modifying Allergy Outcome. Arch Immunol Ther Exp. 2016;64(5):339-47.

27. Gern JE, Reardon CL, Hoffjan S, Nicolae D, Li Z, Roberg KA, et al. Effects of dog ownership and genotype on immune development and atopy in infancy. J Allergy Clin Immunol. 2004;113(2): 307-14. [PubMed: 14767447]

28. Konradsen JR, Fujisawa T, Van Hage M, Hedlin G, Hilger C, Kleine-Tebbe J, et al. Allergy to furry animals: new insights, diagnostic approaches, and challenges. J Allergy Clin Immunol. 2015;135(3):616-25. [PubMed: 25282018]

29. Grönlund H, Adedoyin J, Reininger R, Varga E, Zach M, Fredriksson M, et al. Higher immunoglobulin $\mathrm{E}$ antibody levels to recombinant Fel d 1 in cat-allergic children with asthma compared with rhinoconjunctivitis. Clin Exp Allergy. 2008;38(8):1275-81. [PubMed: 18477016]

30. Ichikawa K, Iwasaki E, Baba M, Chapman M. High prevalence of sensitization to cat allergen among Japanese children with asthma, living without cats. Clin Exp Allergy. 1999;29(6):754-61. [PubMed: 10336590]

31. Wale Meri K Tuli ć, Janet L, Holt PG, Sly PD. Modification of the inflammatory response to allergen challenge after exposure to bacterial lipopolysaccharide. Am J Respir Cell Mol Biol. 2000;22(5):604-12. [PubMed: 10783133]

32. Williams LK, Ownby DR, Maliarik MJ, Johnson CC. The role of endotoxin and its receptors in allergic disease. Ann Allergy Asthma Immunol. 2005;94(3):323-32. [PubMed: 15801242]

33. Park JH, Spiegelman DL, Burge HA, Gold DR, Chew GL, Milton DK. Longitudinal study of dust and airborne endotoxin in the home. Environ Health Perspect. 2000;108(11):1023-8. [PubMed: 11102291]

34. Bischof W, Koch A, Gehring U, Fahlbusch B, Wichmann H, Heinrich J. Predictors of high endotoxin concentrations in the settled dust of German homes. Indoor Air. 2002;12(1):2-9. [PubMed: 11951708] 


\section{HIGHLIGHTS}

\section{What is already known about this topic?}

Exposure to endotoxin as well as exposure to cat and dog have been reported to be associated with asthma and wheeze. However, it has been difficult to separate the two exposures and how pets influence the association of endotoxin with asthma and wheeze is unclear.

\section{What does this article add to our knowledge?}

Exposure to dog allergen enhances endotoxin association with wheeze in participants not sensitized to dog. In individuals sensitized to cat and exposed to cat allergen, endotoxin is associated with asthma. In all participants, co-exposure to dog and cat allergens increased endotoxin association with asthma and wheeze.

\section{How does this study impact current management guidelines?}

Measures aimed at decreasing the levels of endotoxin and dog and cat allergens in the homes of people who own pets, as all three should be targeted to reduce active asthma and wheeze long term. 

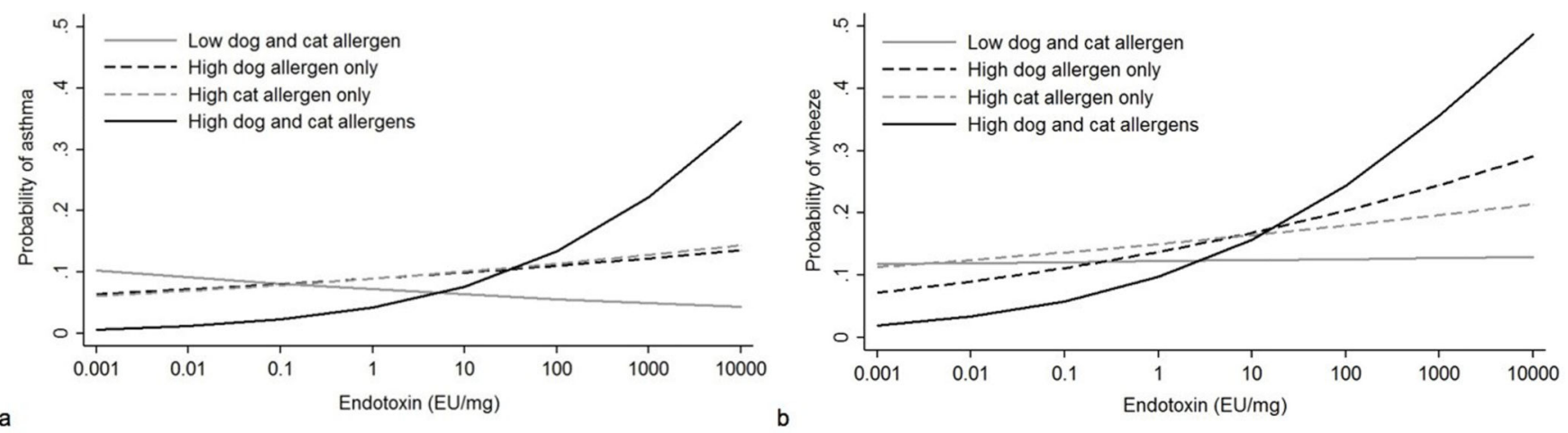

Figure 1:

Change in the probability of current asthma (a) and wheeze in the past 12 months (b) with increasing concentration of endotoxin by exposure to dog and cat allergens. The graph shows that the probability of the outcomes associated with endotoxin increases more significantly with high exposure to dog and cat allergens than with low exposure to dog and/or cat allergens. 

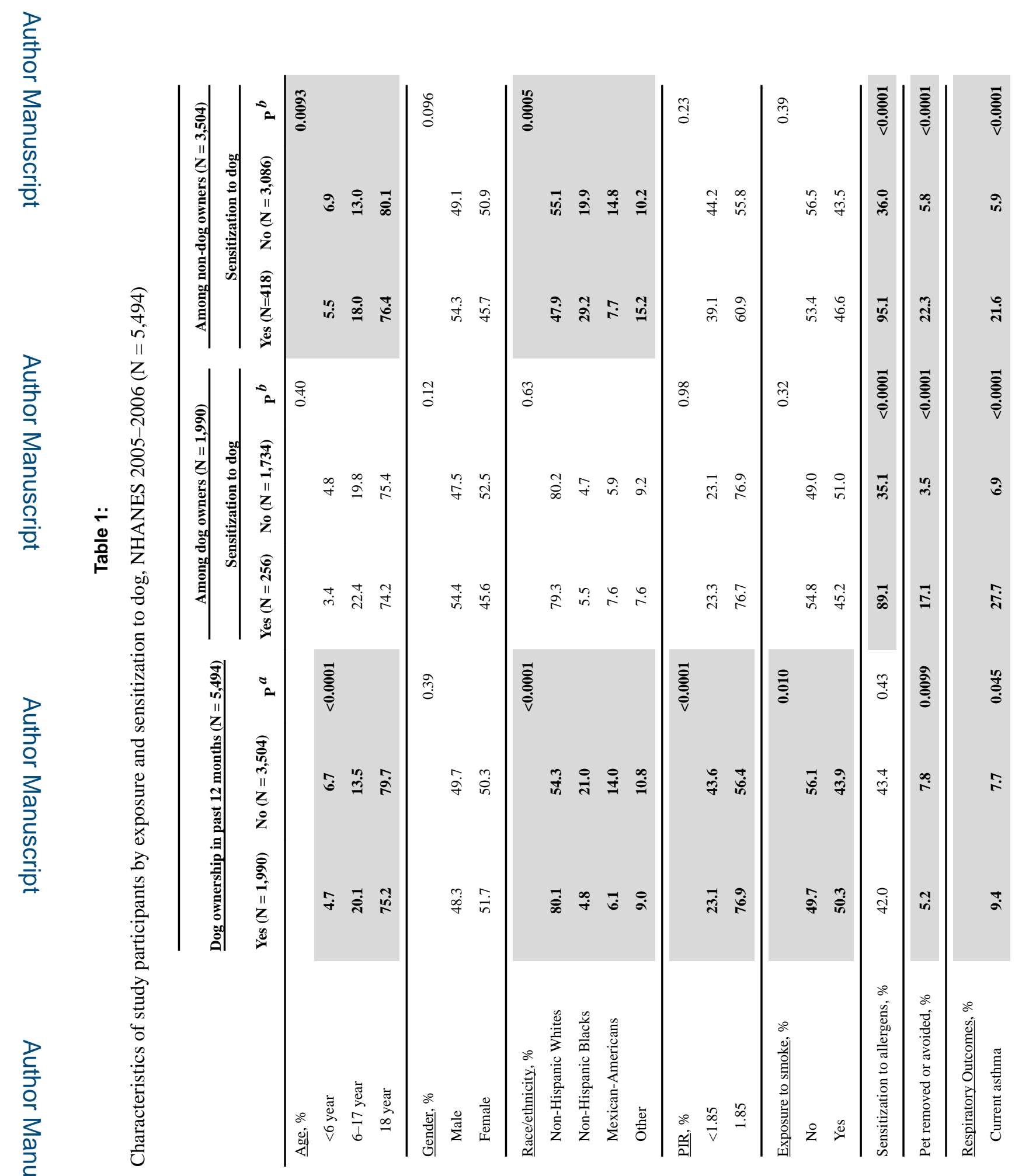

J Allergy Clin Immunol Pract. Author manuscript; available in PMC 2019 November 01. 


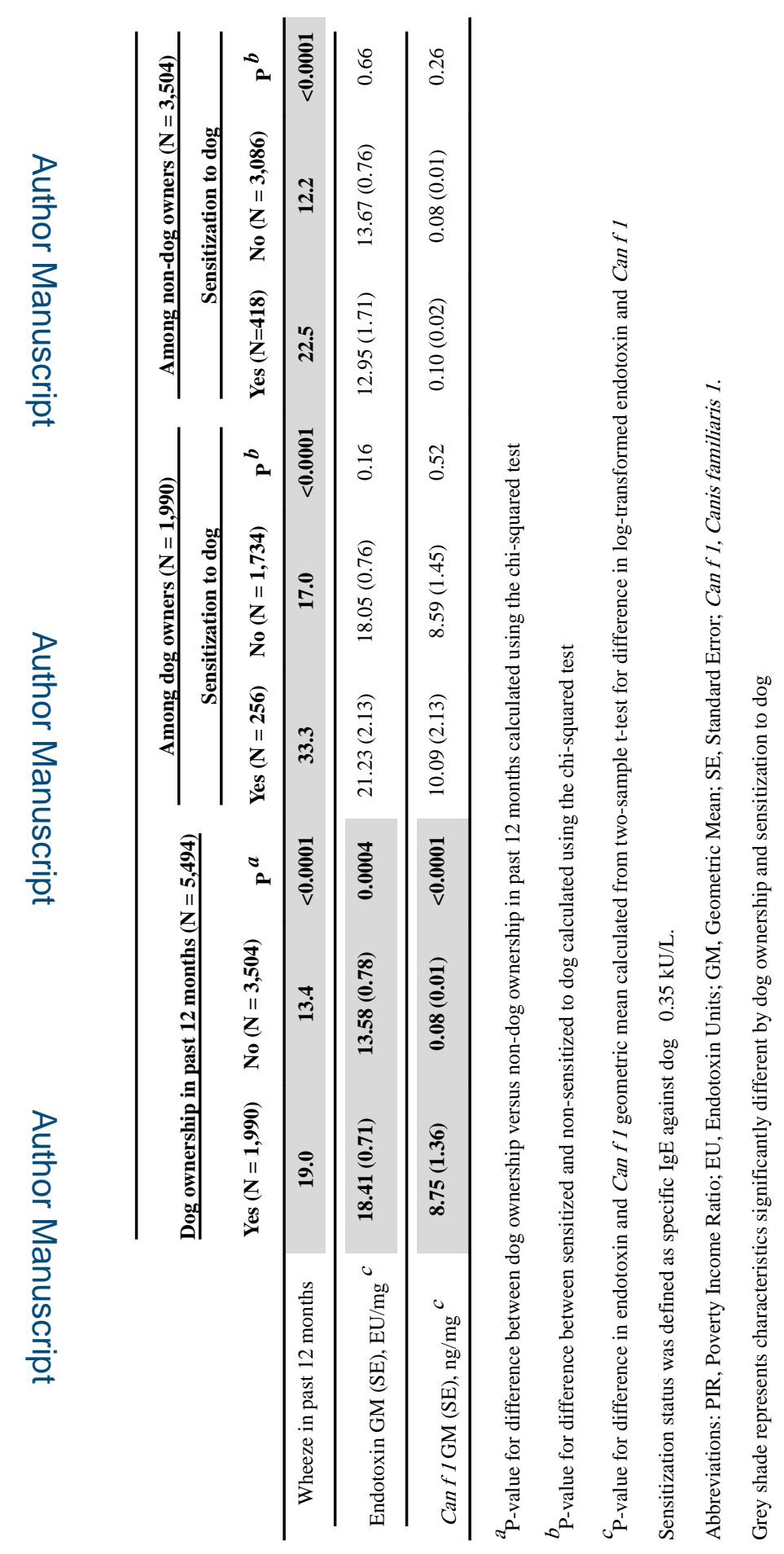

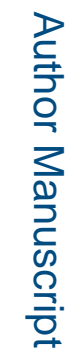



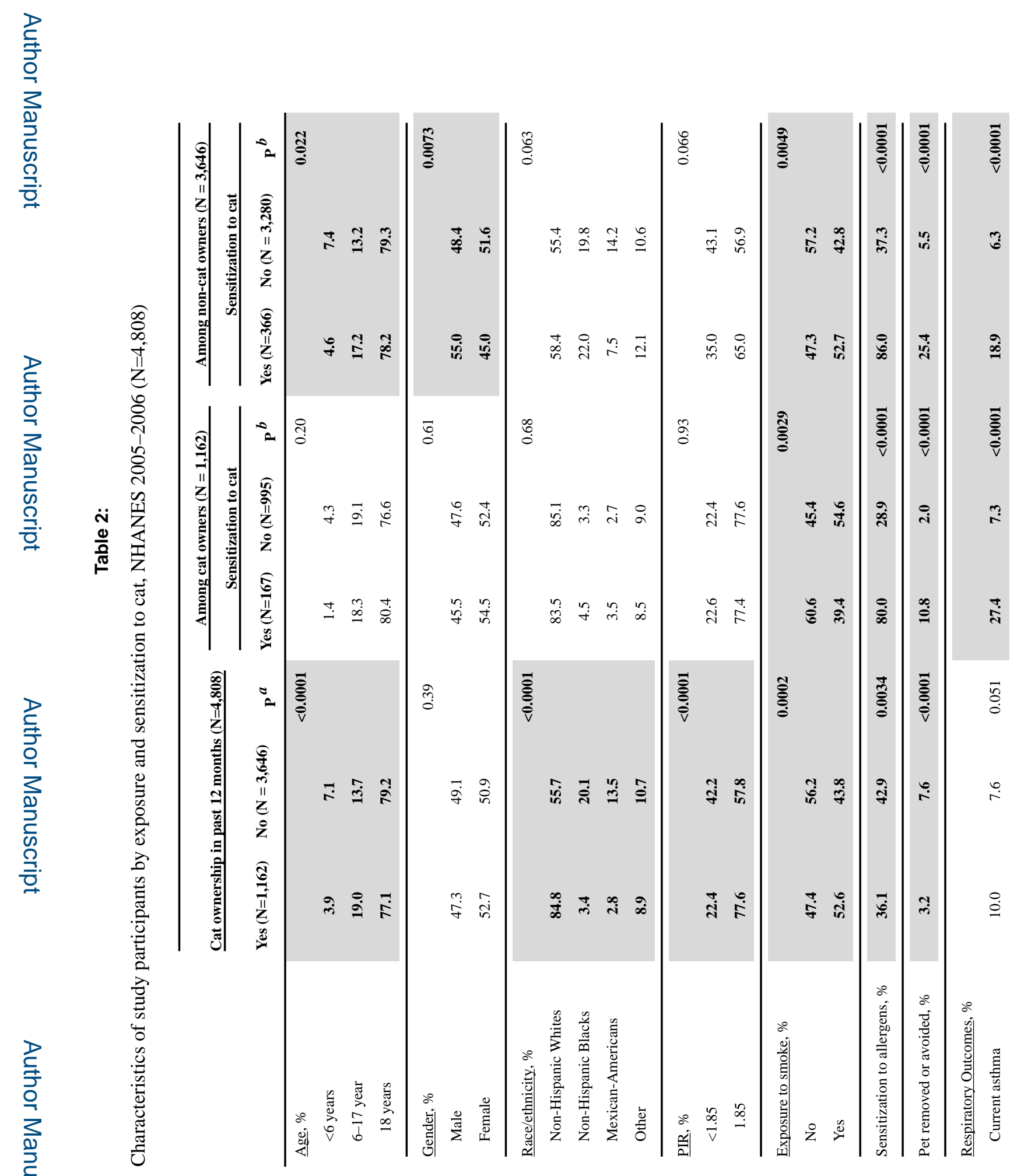

J Allergy Clin Immunol Pract. Author manuscript; available in PMC 2019 November 01. 


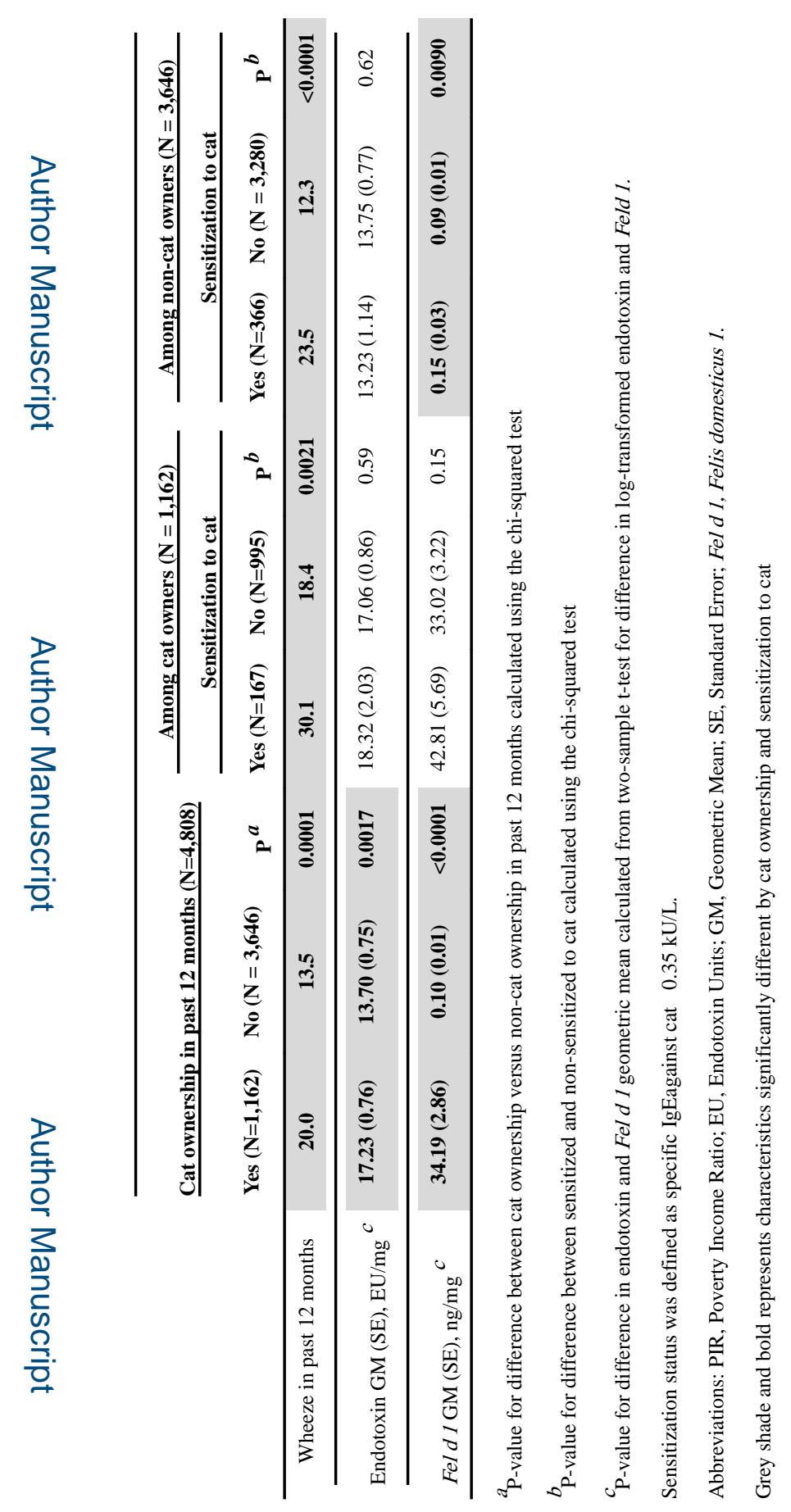

로을 
Table 3:

Associations of endotoxin, dog, and cat exposure and sensitization with asthma and wheeze, NHANES 20052006.

\begin{tabular}{|c|c|c|c|c|}
\hline & \multicolumn{2}{|c|}{ Current asthma } & \multicolumn{2}{|c|}{ Wheeze in past 12 months } \\
\hline & OR $(95 \% \mathrm{CI})$ & $\mathbf{P}$ & OR $(95 \% \mathrm{CI})$ & $\mathbf{P}$ \\
\hline \multicolumn{5}{|l|}{ In all participants } \\
\hline Endotoxin & $1.19(0.98,1.45)$ & 0.084 & $1.30(1.04,1.62)$ & 0.019 \\
\hline \multicolumn{5}{|l|}{ Dog exposure } \\
\hline Dog ownership & $1.34(0.99,1.81)$ & 0.059 & $1.50(1.17,1.91)$ & 0.0012 \\
\hline Dog allergen & $1.09(0.99,1.20)$ & 0.079 & $1.11(1.05,1.19)$ & 0.0009 \\
\hline Sensitization to dog & $3.08(1.57,6.01)$ & 0.0010 & $1.82(1.44,2.28)$ & $<0.0001$ \\
\hline \multicolumn{5}{|l|}{ Cat exposure } \\
\hline Cat ownership & $1.59(1.15,2.19)$ & 0.0049 & $1.71(1.22,2.39)$ & 0.0018 \\
\hline Cat allergen & $1.10(1.00,1.21)$ & 0.048 & $1.12(1.01,1.25)$ & 0.033 \\
\hline$\underline{\text { Sensitization to cat }}$ & $2.35(1.55,3.54)$ & $<0.0001$ & $1.59(1.23,2.06)$ & 0.0004 \\
\hline \multicolumn{5}{|c|}{$\underline{\text { In children }<6 \text { years old }}$} \\
\hline$\underline{\text { Log-endotoxin }}$ & $1.35(0.83,2.19)$ & 0.23 & $1.05(0.61,1.81)$ & 0.86 \\
\hline \multicolumn{5}{|l|}{$\underline{\text { Dog exposure }}$} \\
\hline Dog ownership & $0.26(0.10,0.72)$ & 0.0091 & $0.67(0.33,1.39)$ & 0.29 \\
\hline $\log -\operatorname{Can} f 1$ & $0.94(0.64,1.37)$ & 0.74 & $0.93(0.75,1.16)$ & 0.53 \\
\hline Sensitization to dog & $0.93(0.19,4.50)$ & 0.92 & $1.00(0.34,2.95)$ & 0.99 \\
\hline \multicolumn{5}{|l|}{ Cat exposure } \\
\hline Cat ownership & $0.74(0.29,1.90)$ & 0.53 & $1.21(0.53,2.79)$ & 0.65 \\
\hline Log-Feld 1 & $0.96(0.74,1.25)$ & 0.78 & $1.05(0.85,1.31)$ & 0.63 \\
\hline$\underline{\text { Sensitization to cat }}$ & $1.41(0.26,7.74)$ & 0.69 & $0.36(0.12,1.08)$ & 0.68 \\
\hline \multicolumn{5}{|c|}{ In children 6-17 years old } \\
\hline$\underline{\text { Log-endotoxin }}$ & $1.66(0.90,3.05)$ & 0.10 & $1.77(1.09,2.88)$ & 0.021 \\
\hline \multicolumn{5}{|l|}{$\underline{\text { Dog exposure }}$} \\
\hline Dog ownership & $1.53(0.94,2.49)$ & 0.086 & $1.19(0.74,1.92)$ & 0.48 \\
\hline $\log -\operatorname{Can} f 1$ & $1.14(0.89,1.45)$ & 0.29 & $1.06(0.87,1.30)$ & 0.56 \\
\hline Sensitization to dog & $2.26(1.32,3.87)$ & 0.0030 & $2.02(1.25,3.28)$ & 0.0042 \\
\hline \multicolumn{5}{|l|}{ Cat exposure } \\
\hline Cat ownership & $1.39(0.75,2.59)$ & 0.30 & $1.15(0.70,1.88)$ & 0.59 \\
\hline Log-Feld 1 & $1.01(0.89,1.16)$ & 0.83 & $1.03(0.90,1.17)$ & 0.68 \\
\hline$\underline{\text { Sensitization to cat }}$ & $2.56(1.42,4.61)$ & 0.0017 & $1.86(1.02,3.41)$ & 0.044 \\
\hline \multicolumn{5}{|c|}{$\underline{\text { In adults } \not 18 \text { years old }}$} \\
\hline$\underline{\text { Log-endotoxin }}$ & $1.08(0.85,1.37)$ & 0.52 & $1.28(1.01,1.62)$ & 0.045 \\
\hline \multicolumn{5}{|l|}{ Dog exposure } \\
\hline Dog ownership & $1.51(1.11,2.05)$ & 0.0079 & $1.74(1.30,2.32)$ & 0.0002 \\
\hline $\log -\operatorname{Can} f 1$ & $1.10(0.99,1.21)$ & 0.069 & $1.15(1.07,1.24)$ & $<0.0001$ \\
\hline
\end{tabular}




\begin{tabular}{|c|c|c|c|c|}
\hline & \multicolumn{2}{|c|}{ Current asthma } & \multicolumn{2}{|c|}{ Wheeze in past 12 months } \\
\hline & OR $(95 \% \mathrm{CI})$ & $\mathbf{P}$ & OR $(95 \% \mathrm{CI})$ & $\mathbf{P}$ \\
\hline Sensitization to dog & $3.72(1.76,7.84)$ & 0.0006 & $1.86(1.32,2.61)$ & 0.0004 \\
\hline \multicolumn{5}{|l|}{ Cat exposure } \\
\hline Cat ownership & $1.84(1.24,2.73)$ & 0.0025 & $2.00(1.25,3.20)$ & 0.0039 \\
\hline Log-Feld 1 & $1.13(1.01,1.27)$ & 0.031 & $1.14(1.01,1.29)$ & 0.030 \\
\hline$\underline{\text { Sensitization to cat }}$ & $2.41(1.56,3.73)$ & $<0.0001$ & $1.65(1.26,2.15)$ & 0.0003 \\
\hline
\end{tabular}

Abbreviations: OR, odds ratio; CI, Confidence Interval; Can $\mathrm{f}$ 1, Canis familiaris 1; Fel d 1, Felis domesticus 1

Models adjusted for age, gender, race/ethnicity, poverty income ratio, exposure to cigarette smoke, pet removal or avoidance, sensitization to other allergens, and endotoxin. Odds ratios for endotoxin, dog and cat allergens reported for a 10-fold increase.

Grey shade and bold represent significant odds ratios and p-values 


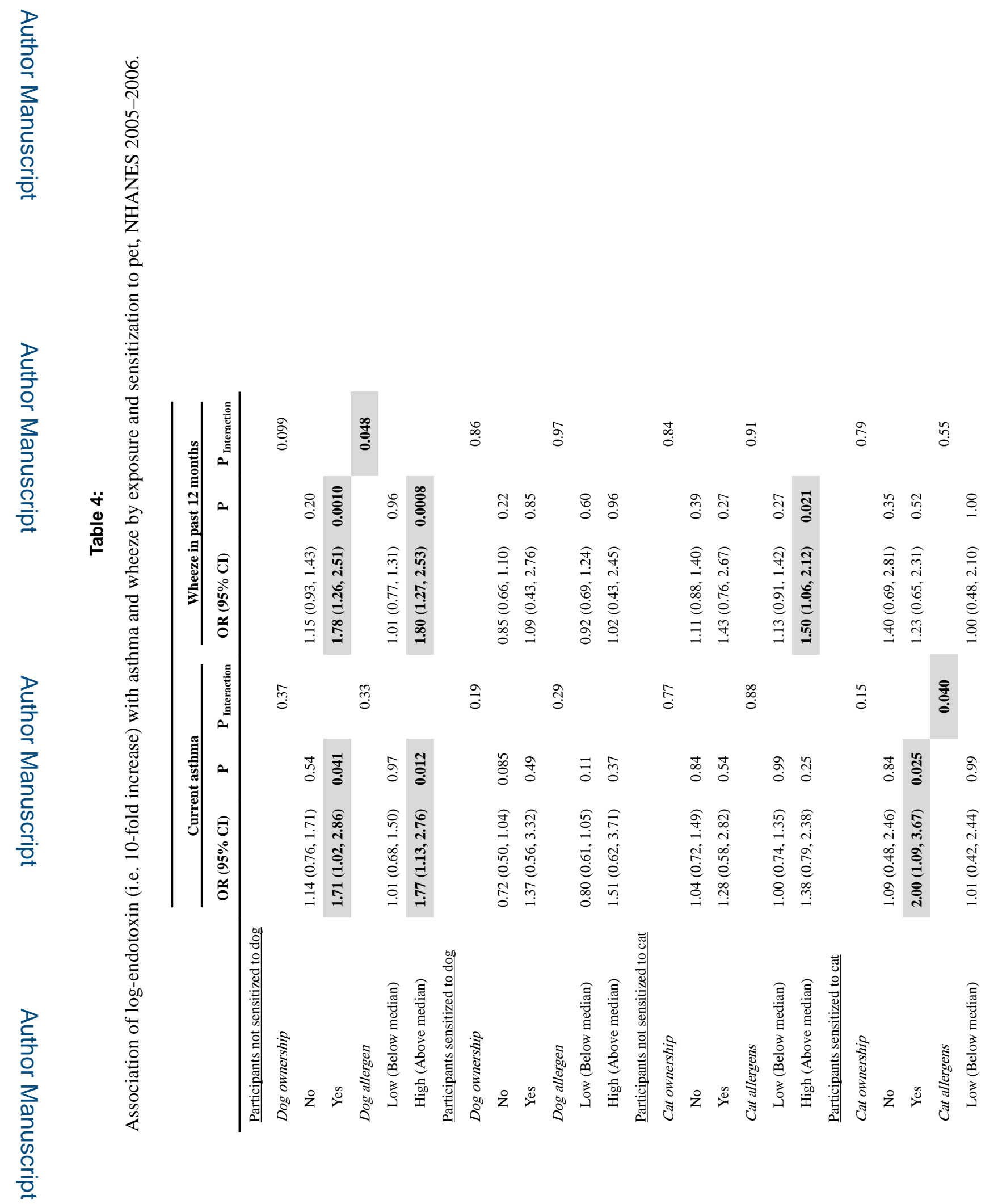

J Allergy Clin Immunol Pract. Author manuscript; available in PMC 2019 November 01. 


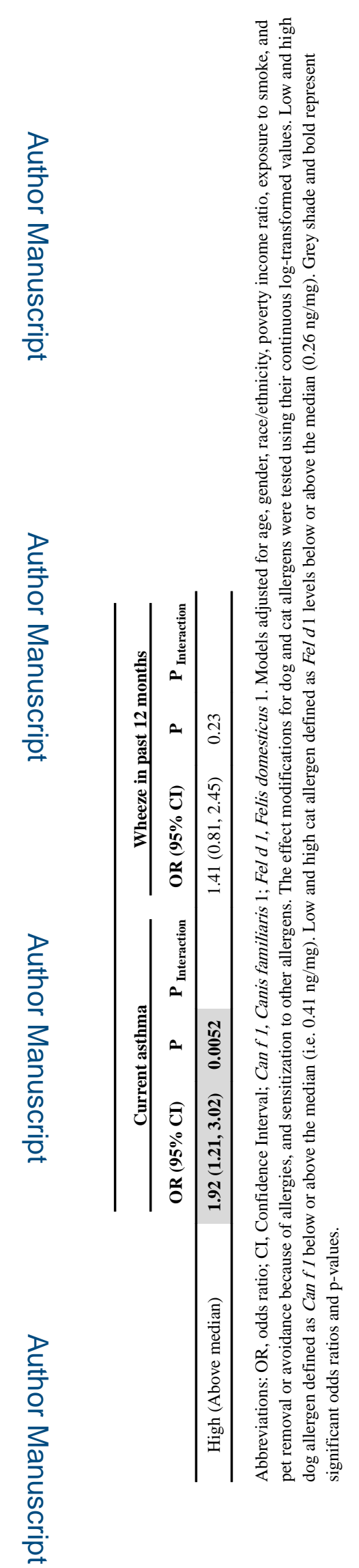

J Allergy Clin Immunol Pract. Author manuscript; available in PMC 2019 November 01. 


\section{롤 \\ 롬ำ}

롱

항 흘

曾

言总总

잉

을

政

O일

눈

突

을 핼

矛

รีํㅇ

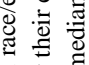

壱

吅

s.

훙

要

蛋

政

密

돈

(⿹勹巳)

$\because 7$

零

\%

i

ए



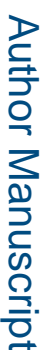

जे

的

ब

突

站势

ปิ

政总

递它总

通离

言 흥

च 0

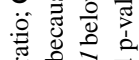

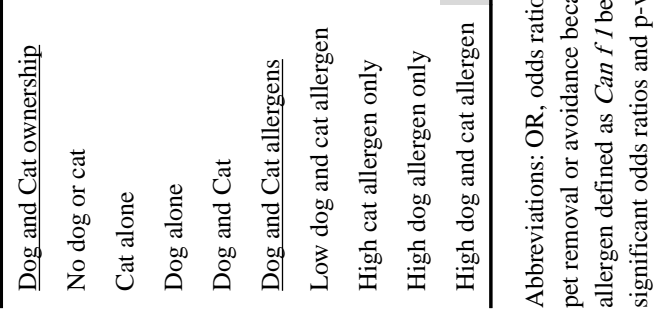

J Allergy Clin Immunol Pract. Author manuscript; available in PMC 2019 November 01. 